\title{
Synthesis and Spectroscopic and Antimicrobial Studies of Schiff Base Metal Complexes Derived from 2-Hydroxy-3-methoxy-5-nitrobenzaldehyde
}

\author{
K. R. Joshi, ${ }^{1}$ A. J. Rojivadiya, ${ }^{1}$ and J. H. Pandya ${ }^{2}$ \\ ${ }^{1}$ Department of Chemistry, M.D. Science College, Porbandar, Gujarat 360575, India \\ ${ }^{2}$ Department of Chemistry, Shree D.K.V. Arts \& Science College, Jamnagar, Gujarat 361008, India \\ Correspondence should be addressed to A. J. Rojivadiya; lekhrajr@gmail.com and J. H. Pandya; jhpandya@gmail.com
}

Received 22 July 2014; Revised 13 October 2014; Accepted 14 October 2014; Published 17 November 2014

Academic Editor: Daniel L. Reger

Copyright (C) 2014 K. R. Joshi et al. This is an open access article distributed under the Creative Commons Attribution License, which permits unrestricted use, distribution, and reproduction in any medium, provided the original work is properly cited.

Two new series of copper(II) and nickel(II) complexes with two new Schiff base ligands 2-((2,4-dimethylphenylimino)methyl)-6methoxy-4-nitrophenol and 2-((3,4-difluorophenylimino)methyl)-6-methoxy-4-nitrophenol have been prepared. The Schiff base ligands were synthesized by the condensation of 2-hydroxy-3-methoxy-5-nitrobenzaldehyde with 2,4-dimethylaniline or 3,4difluoroaniline. The ligands and their metal complexes have been characterized by IR, ${ }^{1} \mathrm{H}$ NMR, mass and electronic spectra and TG analysis. The Schiff base ligands and their metal complexes were tested for antimicrobial activity against Gram positive bacteria Staphylococcus aureus, and Streptococcus pyogenes and Gram negative bacteria Escherichia coli, and Pseudomonas aeruginosa and fungus Candida albicans, Aspergillus niger, and Aspergillus clavatus using Broth Dilution Method.

\section{Introduction}

Vanillin and o-vanillin are such natural compounds which have both phenolic $\mathrm{OH}$ and aldehyde group. They are positional isomers, in which $\mathrm{O}$-vanillin shows contradictory effects. There are several reports indicating that o-vanillin induces mutations and it has also been found to enhance chromosomal aberrations in in vitro systems [1-4]. Schiff bases derived from 2-hydroxy-3-methoxybenzaldehyde (o-vanillin) have not been investigated so thoroughly. The mono- and bis-Schiff bases of $o$-vanillin and 2,3diaminopyridine have been used as ionophores in a $\mathrm{Cu}$ (II) selective electrochemical sensor [5]. These compounds as well as their metal complexes have been found to possess biological activity [6]. Antibacterial activity has also been reported for the ruthenium(II) complex of the Schiff base of $o$-vanillin and 2-aminopyridine [7]. Furthermore, the Schiff bases are very important tools for the inorganic chemists as they are widely used to design molecular ferromagnets as well as in biological modeling applications. They are also used as liquid crystals and heterogeneous catalysts [8-10]. Schiff base ligands containing various donor atoms (like N,
$\mathrm{O}, \mathrm{S}$, etc.) show broad biological activity and are of special interest because of the variety of ways in which they are bonded to the transition metal ions $[11,12]$.

\section{Materials and Methods}

2-Hydroxy-3-methoxy-5-nitrobenzaldehyde was synthesized according to the method reported in the literature [13]. Copper(II) and nickel(II) were used as nitrate salts and were obtained from Rankem. All amines were used from Merck; organic solvents $\mathrm{EtOH}, \mathrm{MeOH}, \mathrm{DMF}$, and DMSO were of reagent grade.

2.1. Physical Measurements. IR spectra $\left(4000-400 \mathrm{~cm}^{-1}\right)$ of the ligands and metal complexes were obtained using $\mathrm{KBr}$ discs, on 8400 FT-IR SHIMADZU spectrometer. Mass spectra were recorded on QP 2010 SHIMADZU GCMS spectrometer. ${ }^{1} \mathrm{H}$ NMR spectra of ligands were recorded on Bruker Avance-II $400 \mathrm{MHz}$ FT-NMR spectrometer using TMS as an internal standard and $\mathrm{CDCl}_{3}$ as a solvent. ESI mass spectra of complexes were recorded by VG-70S Spectrometer. 
Electronic spectra of the metal complexes in DMF were recorded on a Perkin Elmer Lambda 19 spectrophotometer and molar conductance of the metal complexes was determined on Systronics direct reading conductivity meter type CM-82T. A simultaneous TG/DTA was recorded on Perkin Elmer Pyris-1 model. DSC was carried out on Perkin Elmer Pyris-7 instrument. Elemental analysis $(\mathrm{C}, \mathrm{H}$, and $\mathrm{N})$ was carried out on elemental analyzer PERKIN ELMER 2400, while analysis of metal was also carried out by EDTA titration method, in which the metal complex first evaporates in conc. nitric acid and prepares a stock solution. This solution with ammonia then titrates against EDTA by using appropriate indicator. The M.P. of ligands was carried out by standard laboratory thermometer. Magnetic susceptibility measurements of the complexes were carried out by Gouy balance using $\mathrm{Hg}\left[\mathrm{Co}(\mathrm{CN})_{4}\right]$ as calibrant. IR and mass spectra and elemental analysis of compounds were done in Department of Chemistry, Saurashtra University, Rajkot. TG-DTA-DSC was carried out in Department of Physics, Saurashtra University, Rajkot. ${ }^{1} \mathrm{H}$ NMR and ESI mass spectra of compounds were carried out in SAIF, Chandigarh. Electronic spectra and conductance measurement of compounds were done in the Department of Chemistry, DKV College, Jamnagar.

\subsection{Preparation of Schiff Base Ligands}

2.2.1. Synthesis of 2-((2,4-Dimethylphenylimino)methyl)-6methoxy-4-nitrophenol (MPM). The Schiff base ligand MPM was synthesized by adding 2-hydroxy-3-methoxy-5nitrobenzaldehyde $(4.9 \mathrm{~g} 25 \mathrm{mmol})$ dissolved in hot absolute EtOH $\left(20 \mathrm{~cm}^{3}\right)$ to 2,4-dimethylaniline $(3.0 \mathrm{~g}, 25.0 \mathrm{mmol})$ in absolute EtOH $\left(20 \mathrm{~cm}^{3}\right)$. The reaction mixture was heated to reflux for $4 \mathrm{~h}$. The products obtained were filtered off and washed several times with $\mathrm{EtOH}$ and then ether and air dried. The products were kept in desiccators until used. Recrystallization was carried out in EtOH. The progress of reaction was monitored by TLC.

\subsubsection{Synthesis of 2-((3,4-Difluorophenylimino)methyl)-6-} methoxy-4-nitrophenol (FPM). The Schiff base ligand FPM was synthesized by adding 2-hydroxy-3-methoxy-5nitrobenzaldehyde $(4.9 \mathrm{~g} 25 \mathrm{mmol})$ dissolved in hot absolute $\mathrm{EtOH}\left(20 \mathrm{~cm}^{3}\right)$ to 3,4 -difluoroaniline $(3.2 \mathrm{~g}, 25.0 \mathrm{mmol})$ in absolute EtOH $\left(20 \mathrm{~cm}^{3}\right)$. The reaction mixture was heated to reflux for $4 \mathrm{~h}$. The products obtained were filtered off and washed several times with $\mathrm{EtOH}$ and then ether and air dried. The products were kept in desiccators until used. Recrystallization was carried out in EtOH. The progress of reaction was monitored by TLC.

2.3. Preparation of Metal Complexes. All the metal complexes of Schiff base ligands were prepared by the following method. The metal salt was dissolved in water and the solution was added to a hot ethanolic solution of the corresponding Schiff bases. After the complete addition little amount of sodium acetate was added and the mixture was refluxed for $4 \mathrm{~h}$. A crystalline solid was obtained, which was isolated by

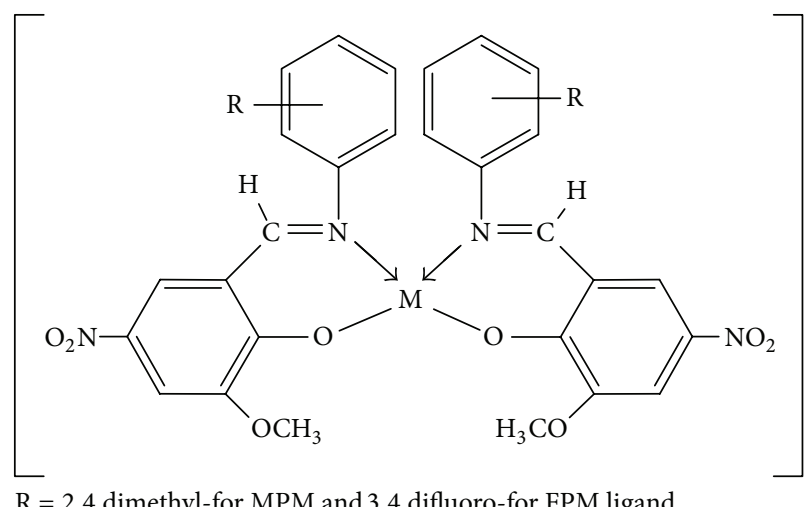

$\mathrm{R}=$ 2,4 dimethyl-for MPM and 3,4 difluoro-for FPM ligand $\mathrm{M}=\mathrm{Ni}(\mathrm{II}), \mathrm{Cu}(\mathrm{II})$

SCHEME 1: General structure of metal complex.

filtration, washed with hot water, and dried in air. The general structure of the metal complexes is given in Scheme 1.

2.4. Antimicrobial Screening. All newly synthesized compounds were tested for their antibacterial activities against Gram positive bacteria Staphylococcus aureus and Streptococcus pyogenes and Gram negative bacteria Escherichia coli and Pseudomonas aeruginosa and antifungal activity against Candida albicans, Aspergillus niger, and Aspergillus clavatus. The method used to evaluate the antimicrobial activity was "Broth Dilution Method." It is one of the nonautomated in vitro susceptibility tests. The MIC (minimal inhibitory concentration) of the control organism is read to check the accuracy of the drug concentrations. The lowest concentration inhibiting growth of the organism is recorded as the MIC. The MIC values of the newly synthesized compounds have been compared with the standard drugs ampicillin, chloramphenicol, nystatin, and griseofulvin [14].

\section{Results and Discussion}

The Schiff base ligands MPM and FPM were prepared by the condensation of 2-hydroxy-3-methoxy-5-nitrobenzaldehyde with 2,4-dimethylaniline and 3,4-difluoroaniline in molar ratio $1: 1$. The formation of Schiff bases and their metal complexes were confirmed by various analytical techniques such as IR, ${ }^{1} \mathrm{H}$ NMR, mass, and electronic spectra, conductance, and TG-DT analysis. Table 1 lists the physical and analytical data of the Schiff bases and their metal complexes. The antimicrobial activities of Schiff base ligands and metal complexes are listed in Tables 2(a) and 2(b).

3.1. Characterization of the Ligands. The IR spectra of Schiff base ligands are depicted in Figures 1(a) and 1(b). The IR spectra of the ligands show a broad band at $3420-3460 \mathrm{~cm}^{-1}$ due to the stretching vibrations of phenolic hydroxyl group. The broadness is due to intermolecular hydrogen bonding between the phenolic group and the azomethine group. The strong band observed at $1614 \mathrm{~cm}^{-1}$ is assigned to the stretching vibrations of the azomethine group. Two moderately 


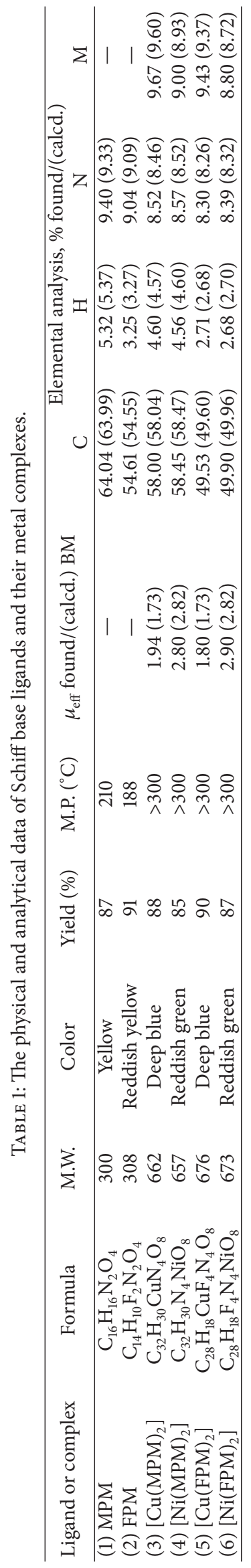


TABLE 2: (a) Antibacterial activity of Schiff bases and their metal complexes. (b) Antifungal activity of Schiff base ligands and their metal complexes.

(a)

\begin{tabular}{|c|c|c|c|c|c|}
\hline \multicolumn{6}{|c|}{ Minimal inhibition concentration (MIC) $(\mathrm{g} / \mathrm{mL})$} \\
\hline Sr number & Lioand/complex & E. coli & P. aeruginosa & S. aureus & S. pyogenes \\
\hline ग1. 11U1100е & Ligand/Compiex & MTCC-443 & MTCC-441 & MTCC-96 & MTCC- 442 \\
\hline 1 & MPM & 250 & 250 & 250 & 250 \\
\hline 2 & FPM & 250 & 100 & 250 & 250 \\
\hline 3 & {$\left[\mathrm{Cu}(\mathrm{MPM})_{2}\right]$} & 50 & 100 & 150 & 100 \\
\hline 4 & {$\left[\mathrm{Ni}(\mathrm{MPM})_{2}\right]$} & 500 & 500 & 100 & 250 \\
\hline 5 & {$\left[\mathrm{Cu}(\mathrm{FPM})_{2}\right]$} & 125 & 250 & 250 & 100 \\
\hline 6 & {$\left[\mathrm{Ni}(\mathrm{FPM})_{2}\right]$} & 250 & 100 & 50 & 125 \\
\hline \multicolumn{6}{|c|}{ Standard drugs } \\
\hline 1 & Ampicillin & 100 & 100 & 250 & 100 \\
\hline 2 & Chloramphenicol & 50 & 50 & 50 & 50 \\
\hline
\end{tabular}

(b)

\begin{tabular}{|c|c|c|c|c|}
\hline \multicolumn{5}{|c|}{ Minimal inhibition concentration (MIC) $(\mathrm{g} / \mathrm{mL})$} \\
\hline Sr number & Lioand/complex & C. albicans & A. niger & A. clavatus \\
\hline 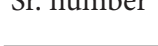 & Liganid/compiex & MTCC-227 & MTCC-282 & MTCC-1323 \\
\hline 1 & MPM & 1000 & 100 & 500 \\
\hline 2 & FPM & 250 & 250 & 250 \\
\hline 3 & {$\left[\mathrm{Cu}(\mathrm{MPM})_{2}\right]$} & 500 & 100 & 500 \\
\hline 4 & {$\left[\mathrm{Ni}(\mathrm{MPM})_{2}\right]$} & 100 & 100 & 250 \\
\hline 5 & {$\left[\mathrm{Cu}(\mathrm{FPM})_{2}\right]$} & 250 & 250 & 100 \\
\hline 6 & {$\left[\mathrm{Ni}(\mathrm{FPM})_{2}\right]$} & 100 & 100 & 250 \\
\hline \multicolumn{5}{|c|}{ Standard drugs } \\
\hline 1 & Nystatin & 100 & 100 & 100 \\
\hline 2 & Griseofulvin & 500 & 100 & 100 \\
\hline
\end{tabular}

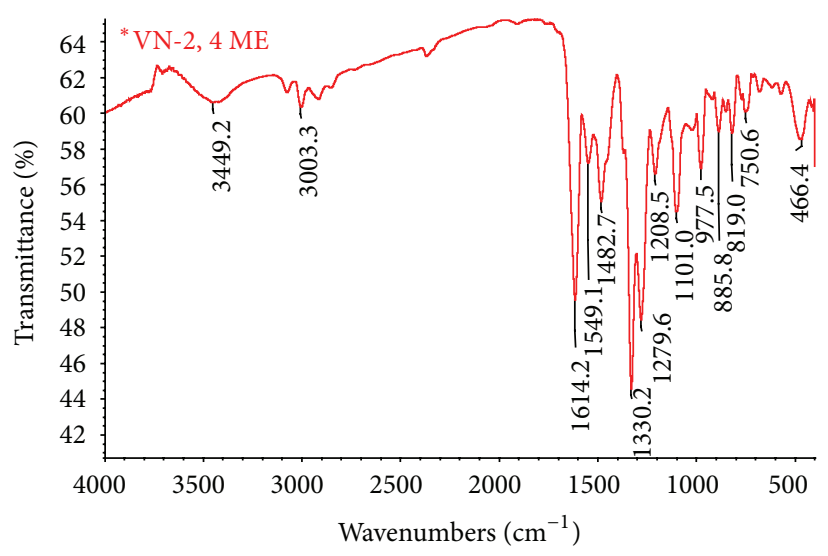

(a)

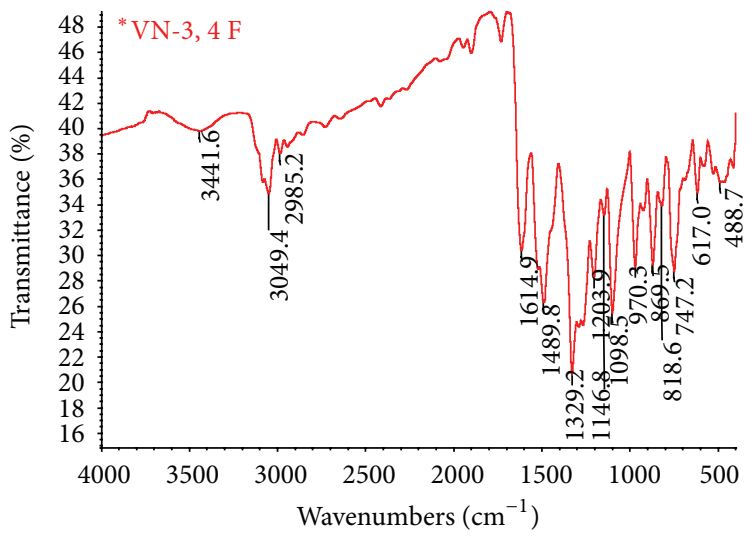

(b)

Figure 1: (a) The IR spectrum of Schiff base ligand MPM. (b) The IR spectrum of Schiff base ligand FPM.

intense bands observed at 3049-3060 and 2985-3005 $\mathrm{cm}^{-1}$ are due to aromatic and aliphatic $v(\mathrm{C}-\mathrm{H})$, respectively $[15$, 16].

The ${ }^{1} \mathrm{H}$ NMR spectra of ligands were recorded in $\mathrm{CDCl}_{3}$. The proton NMR spectrum of one of the ligands is shown in Figure 2. The signal due to methyl protons (ligand MPM) appeared as singlet at $\delta 2.37$ and $2.44 \mathrm{ppm}$, whereas signal due to methoxy protons appeared as singlet in the range $\delta 4.01-4.03 \mathrm{ppm}$. In the aromatic region, a few doublets and in few cases some overlapping doublets/multiplets are observed in the range $\delta 7.12-8.08 \mathrm{ppm}$. These signals are due to aryl protons of benzene rings. The signals due to 


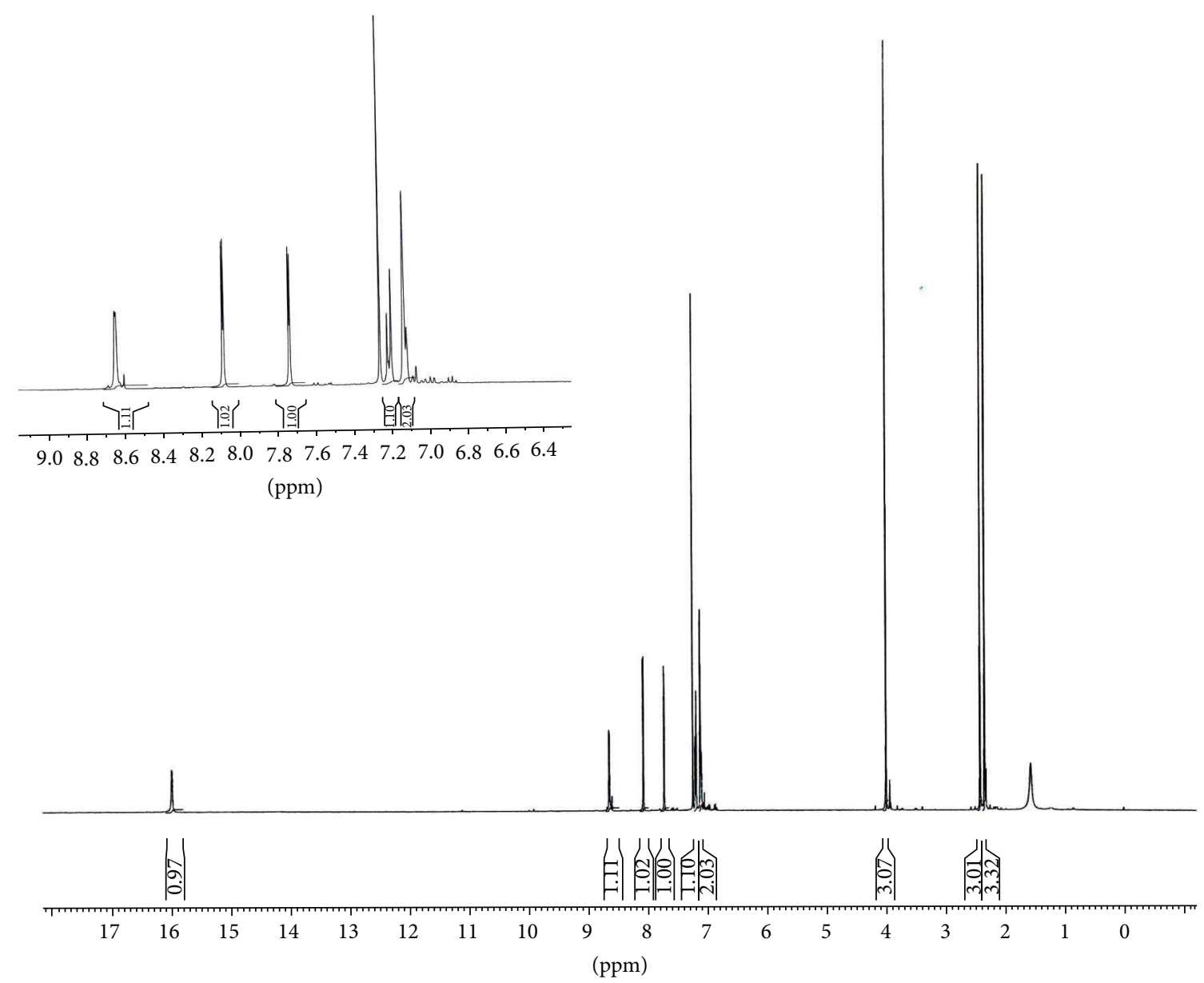

FIgURE 2: ${ }^{1} \mathrm{H}$ NMR spectrum of Schiff base ligand MPM.

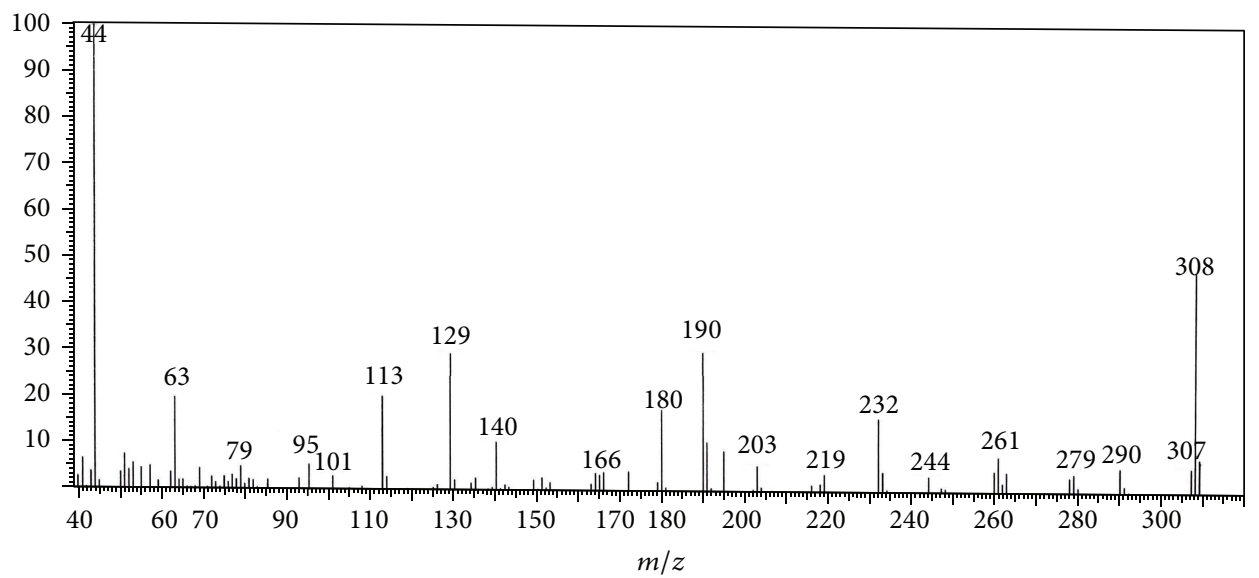

Figure 3: Mass spectrum of Schiff base ligand FPM.

azomethine proton $(-\mathrm{CH}=\mathrm{N}-)$ appeared as singlet at $\delta$ $8.65 \mathrm{ppm}$. Another singlet corresponding to one proton is observed in the range $\delta 14.43-15.98 \mathrm{ppm}$, is due to phenolic $-\mathrm{OH}$ group, and may disappear during complexation $[16,17]$.
The mass spectra of ligands MPM and FPM revealed the molecular ion peak at m/e 300 for the former ligand and $\mathrm{m} / \mathrm{e} 308$ for the latter ligand, which are coincident with the formula weights and support the identity of the structures [18] (Figure 3). 


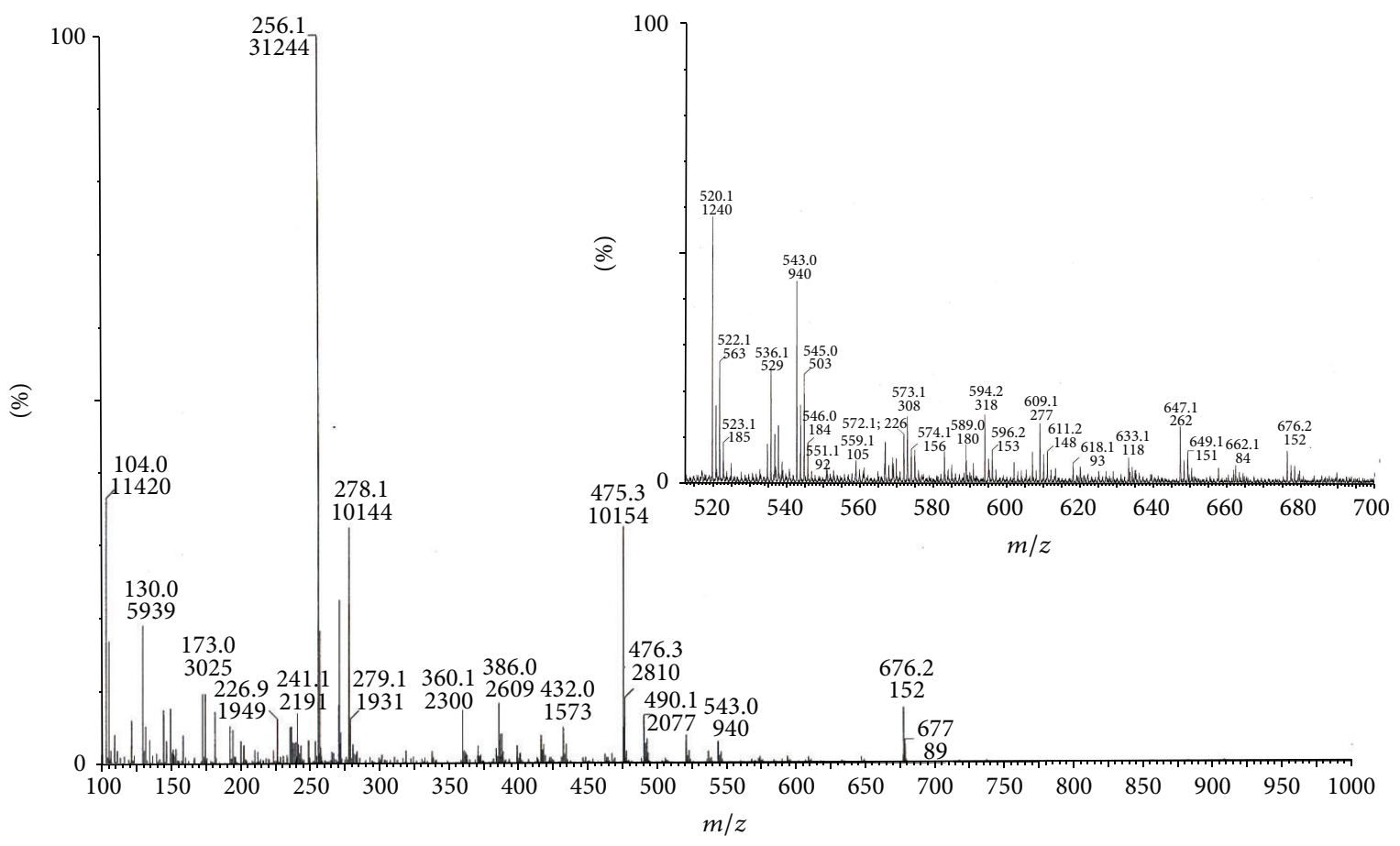

FIGURE 4: ESI mass spectrum of metal complex $\left[\mathrm{Cu}(\mathrm{FPM})_{2}\right]$.

3.2. Characterization of the Metal Complexes. The IR spectra of metal complexes show sharp band in the range 1607$1603 \mathrm{~cm}^{-1}$, which is shifted to lower frequency as compared to ligand, suggesting coordination of the azomethine nitrogen to the metal ion. The disappearance of $v(\mathrm{O}-\mathrm{H})$ shows the deprotonation of the $-\mathrm{OH}$ group and its subsequent coordination to the central metal atom. Two new bands observed at $578-564$ and $481-470 \mathrm{~cm}^{-1}$ are characteristic of $\mathrm{M}-\mathrm{O}$ and M-N absorptions, respectively $[19,20]$.

ESI mass spectra in the positive mode were measured after adding $\mathrm{CsCl}$ to the binuclear $\mathrm{Cu}(\mathrm{II})$ and $\mathrm{Ni}$ (II) neutral complexes in solution (water: methanol = 1:1) [21, 22]. For the ESI-MS of the binuclear complexes the peaks of all complexes are consistent with the calculated isotopic distributions for all the binuclear complexes as in Figure 4.

The observed molar conductance values of the metal (II) complexes in $10^{-3}$ molar DMF solution are in the range $14-29 \Omega^{-1} \mathrm{~cm}^{2} \mathrm{~mol}^{-1}$. The molar conductance values are consistent with the nonelectrolytic nature for all metal complexes [23].

Electronic spectra of all the complexes (Figure 5) were recorded in dimethylformamide (DMF). For square planer $\mathrm{Cu}(\mathrm{II})$, the expected transitions are ${ }^{2} \mathrm{~B}_{1 \mathrm{~g}} \rightarrow{ }^{2} \mathrm{~A}_{1 \mathrm{~g}}$ and ${ }^{2} \mathrm{~B}_{1 \mathrm{~g}} \rightarrow$ ${ }^{2} \mathrm{Eg}$ with respective absorptions at 505-520 and 665-650 $\mathrm{nm}$. Due to Jahn-Teller (J-T) distortions, square planar $\mathrm{Cu}(\mathrm{II})$ complexes give a broad absorption between 600 and $700 \mathrm{~nm}$ and the peak at 505-520 nm merges with the broad band, and thus only one broad band is observed [24]. The Ni(II) complexes showed one strong band at $550 \mathrm{~nm}$, which is assigned to the square planar ${ }^{1} \mathrm{~A}_{1 \mathrm{~g}} \rightarrow{ }^{1} \mathrm{~A}_{2 \mathrm{~g}}$ transition. This

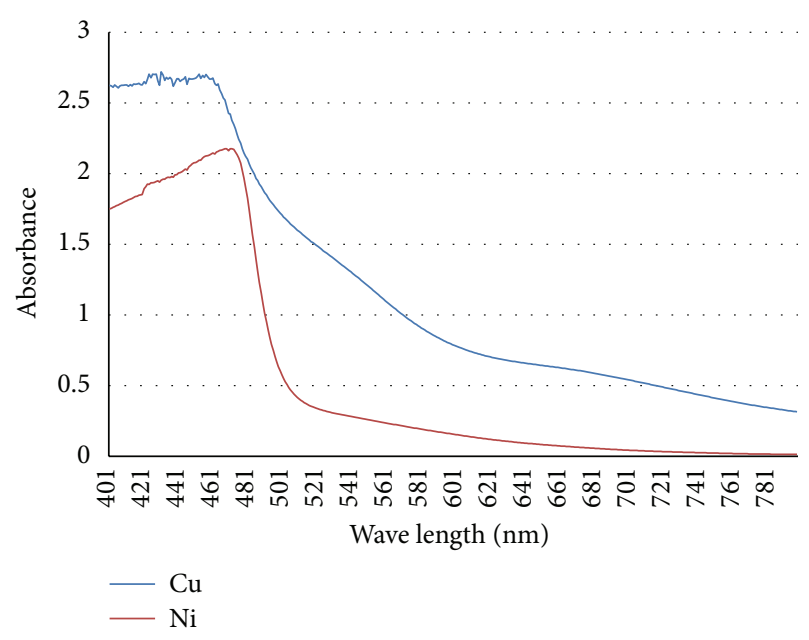

FIgURE 5: Electronic spectra of metal complex.

value lies within the range $600-450 \mathrm{~nm}$ region which is responsible for the reddish color [25].

Thermal analyses of all the complexes were carried out by the TG, DTA, and DSC techniques. The experimental results revealed that the degradation occurred in multiple stages, following a complex mechanism (Figure 6). For each stage the kinetic parameters and the thermogravimetric characteristics have been estimated. Thermal behavior of all complexes explains as follows. The TG curve follows the decrease in sample mass with increase in temperature. In the present investigation heating rates were suitably controlled 


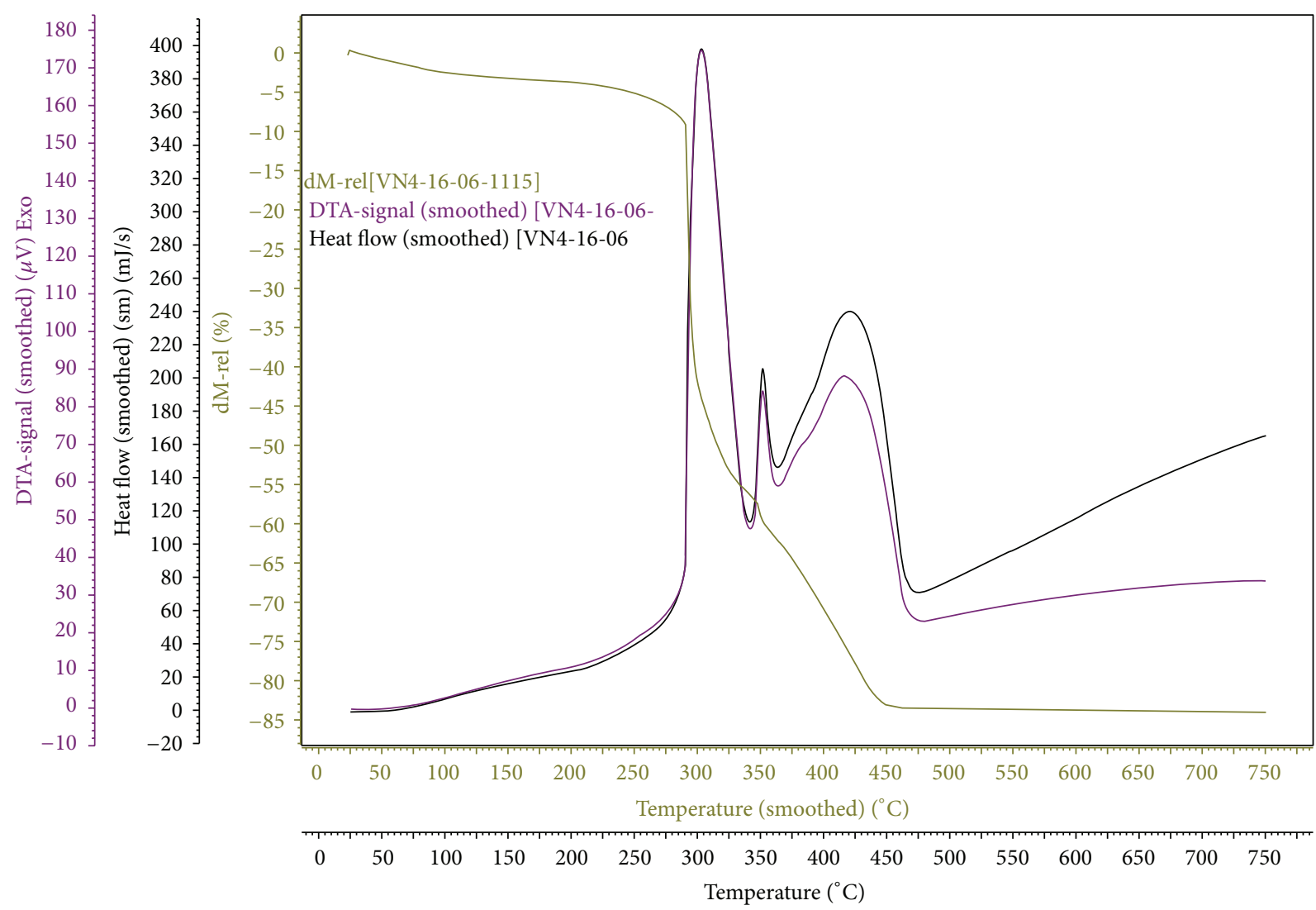

FIGURE 6: TG-DT-DSC analysis of metal complex $\left[\mathrm{Cu}(\mathrm{FPM})_{2}\right]$.

at $5^{\circ} \mathrm{C} \mathrm{min}{ }^{-1}$ and mass loss followed up to $25-800^{\circ} \mathrm{C}$. The complexes slowly started decomposition between 200 and $300^{\circ} \mathrm{C}$. The first mass loss up to $300^{\circ} \mathrm{C}$ is attributed to the removal of two $\mathrm{NO}_{2}$ molecules. This process is accompanied by exothermic process at around $200-320^{\circ} \mathrm{C}$ in DTA curves of all complexes. The mass loss occurring at temperature of $330-500^{\circ} \mathrm{C}$ corresponds to the decomposition of the ligand molecules. The final product of the thermal decomposition at $500-800^{\circ} \mathrm{C}$, metal oxide, was determined by elemental analysis $[18,26]$.

3.3. Antimicrobial Activities. The minimal inhibitory concentration (MIC) against bacteria and fungi of Schiff base ligands and their metal complexes was compared with the MIC values of standard drugs $[14,27,28]$. The results of the biological screening of the ligands and their metal complexes reveal that the antimicrobial activities of the chelated ligands are enhanced as compared to the free ligands (Tables 2(a) and 2(b)).

\section{Conclusion}

On the basis of the above studies, the general structure of the metal complexes is proposed as shown in Scheme 1. The Schiff base ligands are behaving as $\mathrm{O}, \mathrm{N}$ donor bidentate for $\mathrm{Cu}(\mathrm{II})$ and $\mathrm{Ni}(\mathrm{II})$ metal ions. The antimicrobial activity of ligands and metal complexes show good results as compared to standard drugs.

\section{Conflict of Interests}

The authors declare that there is no conflict of interests regarding the publication of this paper.

\section{Acknowledgments}

The authors are thankful to the M.D. Science College, Porbandar, for laboratory facilities, Department of Physics and Department of Chemistry, Saurashtra University, Rajkot, and SAIF, Chandigarh, for providing the analytical services, and the Microcare Laboratory, Surat, for providing antimicrobial activity of compounds. Authors are also thankful to Dr. P. H. Parsania, Head, Department of Chemistry, Saurashtra University, Rajkot.

\section{References}

[1] A. Barik, K. I. Priyadarsini, and H. Mohan, "Redox reactions of 2-hydroxy-3-methoxybenzaldehyde (o-vanillin) in aqueous solution," Radiation Physics and Chemistry, vol. 70, no. 6, pp. 687-696, 2004. 
[2] H. Matsumura, K. Watanabe, and T. Ohta, "o-Vanillin enhances chromosome aberrations induced by alkylating agents in cultured Chinese hamster cells," Mutation Research/Genetic Toxicology, vol. 298, no. 3, pp. 163-168, 1993.

[3] K. Takahashi, M. Sekiguchi, and Y. Kawazoe, "A specific inhibition of induction of adaptive response by $o$-vanillin, a potent comutagen," Biochemical and Biophysical Research Communications, vol. 162, p. 1376, 1989.

[4] K. Watanabe and T. Ohta, "Mutation enhancing effect of ovanillin in the lacZ gene of Escherichia coli: characterization of mutational spectrum," Mutation Research Letters, vol. 302, no. 1, pp. 13-18, 1993.

[5] L. P. Singh and J. M. Bhatnagar, "Copper(II) selective electrochemical sensor based on Schiff Base complexes," Talanta, vol. 64, no. 2, pp. 313-319, 2004.

[6] L. K. W. Henri, J. Tagenine, and B. M. Gupta, "Synthetic and antibacterial studies of Schiff base complexes derived from 2,3diaminopyridine and o-vanillin," Indian Journal of Chemistry A, vol. 40, no. 9, pp. 999-1003, 2001.

[7] K. N. Kumar and R. Ramesh, "Synthesis, characterization, redox property and biological activity of $\mathrm{Ru}(\mathrm{II})$ carbonyl complexes containing O,N-donor ligands and heterocyclic bases," Spectrochimica Acta Part A, vol. 60, no. 12, pp. 2913-2918, 2004.

[8] M. Imran, J. Iqbal, S. Iqbal, and N. Ijaz, "In vitro antibacterial studies of ciprofloxacin-imines and their complexes with $\mathrm{Cu}(\mathrm{II}), \mathrm{Ni}(\mathrm{II}), \mathrm{Co}(\mathrm{II})$, and Zn(II)," Turkish Journal of Biology, vol. 31, no. 2, pp. 67-72, 2007.

[9] G.-J. Kim and J.-H. Shin, "Application of new unsymmetrical chiral Mn(III), Co(II,III) and Ti(IV) salen complexes in enantioselective catalytic reactions," Catalysis Letters, vol. 63, no. 1-2, pp. 83-90, 1999.

[10] B. T. Thaker, P. Patel, A. D. Vansadia, and H. G. Patel, "Synthesis, characterization, and mesomorphic properties of new liquidcrystalline compounds involving ester-azomethine central linkages, lateral substitution, and a thiazole ring," Molecular Crystals and Liquid Crystals, vol. 466, no. 1, pp. 13-22, 2007.

[11] N. Nishat, Asma, and S. Dhyani, "Synthesis, spectral and antimicrobial studies of transition metal complexes with novel macrocyclic ligand containing $\mathrm{C}=\mathrm{N}$ and $\mathrm{CO}-\mathrm{NH}$ group," Journal of Coordination Chemistry, vol. 62, no. 18, pp. 3003-3011, 2009.

[12] P. Krishnamoorthy, P. Sathyadevi, K. Deepa, and N. Dharmaraj, "Studies on the synthesis, spectra, catalytic and antibacterial activities of binuclear ruthenium(II) complexes," Spectrochimica Acta A: Molecular and Biomolecular Spectroscopy, vol. 77, no. 1, pp. 258-263, 2010.

[13] V. K. Ahluwalia, B. Pooja, A. Renu, and C. Ramesh, Intermediates for Organic Synthesis, I.K. International Publishing House, New Delhi, India, 1994.

[14] K. R. Joshi, J. H. Pandya, and A. J. Rojivadiya, "Spectroscopic studies and biological evaluation of transition metal complexes of Schiff bases derived from 5-nitro-o-vanilline," ICAIJ, vol. 4, no. 3, pp. 110-114, 2009.

[15] J. H. Pandya and K. J. Ganatra, "Synthesis, characterization and biological evaluation of bis-bidentate Schiff base metal complexes," Inorganic Chemistry: An Indian Journal, vol. 3, no. 3, pp. 182-187, 2008.

[16] J. C. Lindon, G. E. Tranter, and J. L. Holmes, Encyclopedia of Spectroscopy and Spectrometry, vol. 1, Elsevier, New York, NY, USA, 2000.

[17] I. S. Ahmed and M. A. Kassem, "Synthesis, solvatochromaticity and bioactivities of some transition metal complexes with
2-(R-benzylideneamino)-pyridin-3-ol Schiff base derivatives," Spectrochimica Acta, Part A: Molecular and Biomolecular Spectroscopy, vol. 77, no. 2, pp. 359-366, 2010.

[18] K. M. Vyas, R. N. Jadeja, V. K. Gupta, and K. R. Surati, "Synthesis, characterization and crystal structure of some bidentate heterocyclic Schiff base ligands of 4-toluoyl pyrazolones and its mononuclear $\mathrm{Cu}$ (II) complexes," Journal of Molecular Structure, vol. 990, no. 1-3, pp. 110-120, 2011.

[19] A. A. A. Emara, "Structural, spectral and biological studies of binuclear tetradentate metal complexes of $\mathrm{N}_{3} \mathrm{O}$ Schiff base ligand synthesized from 4,6-diacetylresorcinol and diethylenetriamine," Spectrochimica Acta A: Molecular and Biomolecular Spectroscopy, vol. 77, no. 1, pp. 117-125, 2010.

[20] R. N. Jadeja and N. J. Parmar, "Oxovanadium(IV), Cr(III), $\mathrm{Fe}(\mathrm{III}), \mathrm{Fe}(\mathrm{II}), \mathrm{Ni}(\mathrm{II}), \mathrm{Cu}(\mathrm{II}), \mathrm{Zn}(\mathrm{II})$, and $\mathrm{UO}_{2}(\mathrm{VI})$ chelates from onno donor Schiff base ligand," Synthesis and Reactivity in Inorganic and Metal-Organic Chemistry, vol. 35, pp. 111-117, 2005.

[21] S. Kaizaki, Y. Kato-Igawa, T. Tsukuda, and M. Nakano, "Synthesis and characterization of a series of bis(L-tartrate)-bridged dinuclear transition metal complexes with 2,2/-bipyridine," Journal of Coordination Chemistry, vol. 63, no. 6, pp. 967-976, 2010.

[22] J. H. Pandya, R. N. Jadeja, and K. J. Ganatra, "Spectral characterization and biological evaluation of Schiff bases and their mixed ligand metal complexes derived from 4,6-diacetylresorcinol," Journal of Saudi Chemical Society, vol. 18, no. 3, pp. 190-199, 2014.

[23] B. T. Thaker, K. R. Surati, S. Oswal, R. N. Jadeja, and V. K. Gupta, "Synthesis, spectral, thermal and crystallographic investigations on oxovanadium(IV) and manganese(III) complexes derived from heterocyclic $\beta$-diketone and 2 -amino ethanol," Structural Chemistry, vol. 18, no. 3, pp. 295-310, 2007.

[24] M. R. P. Kurup, S. V. Chandra, and K. Muraleedharan, "Synthesis, spectral and thermal studies of o-vanillin oxime complexes of zinc(II), cadmium(II) and mercury(II)," Journal of Thermal Analysis and Calorimetry, vol. 61, no. 3, pp. 909-914, 2000.

[25] N. P. Moorjani, K. M. Vyas, and R. N. Jadeja, "Synthesis \& characterization of $\mathrm{cu}(\mathrm{ii})$ complexes derived from acyl pyrazolone \& 2-amino phenol," Journal of Pure and Applied Sciences, vol. 18, pp. 68-72, 2010.

[26] M. H. Habibi, E. Askari, M. Amirnasr, A. Amiri, Y. Yamane, and T. Suzuki, "Syntheses, spectral, electrochemical and thermal studies of mononuclear manganese(III) complexes with ligands derived from 1,2-propanediamine and 2-hydroxy-3 or 5-methoxybenzaldehyde: self-assembled monolayer formation on nanostructure zinc oxide thin film," Spectrochimica Acta A: Molecular and Biomolecular Spectroscopy, vol. 79, no. 3, pp. 666671, 2011.

[27] A. Cukurovali, İ. Yilmaz, S. Gur, and C. Kazaz, "Synthesis, antibacterial and antifungal activity of some new thiazolylhydrazone derivatives containing 3-substituted cyclobutane ring," European Journal of Medicinal Chemistry, vol. 41, no. 2, pp. 201207, 2006.

[28] H. Ünver, M. Yıldız, B. Dülger, O. Özgend, E. Kendi, and T. Nuri Durlu, "Spectroscopic studies, antimicrobial activities and crystal structures of N-(2-hydroxy-3-methoxybenzalidene)1aminonaphthalene," Journal of Molecular Structure, vol. 737, no. 2-3, pp. 159-164, 2005. 

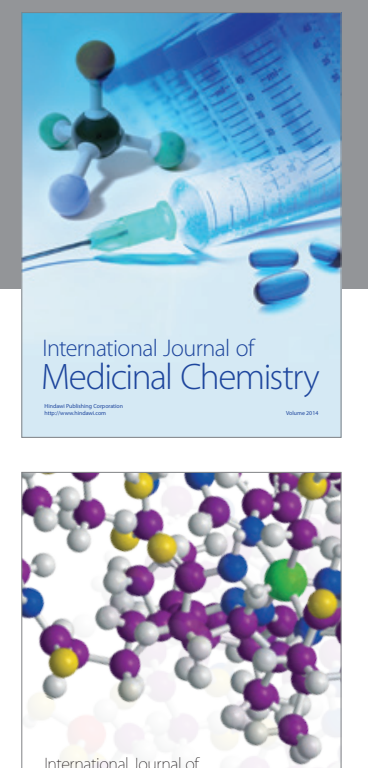

\section{Carbohydrate} Chemistry

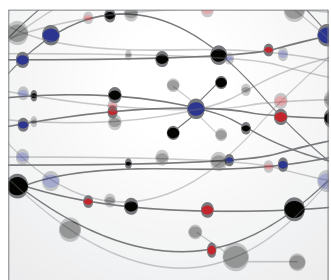

The Scientific World Journal
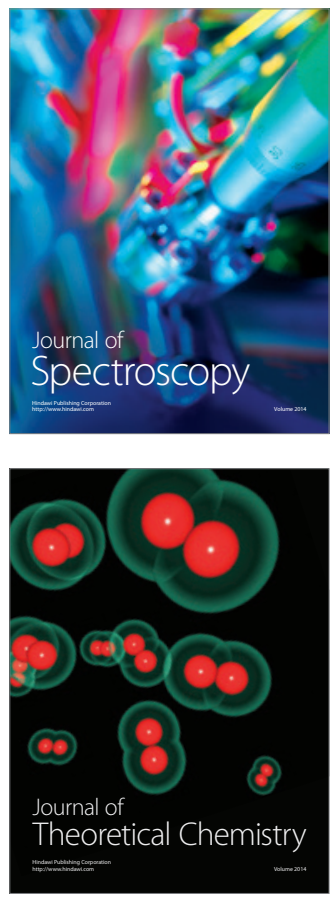
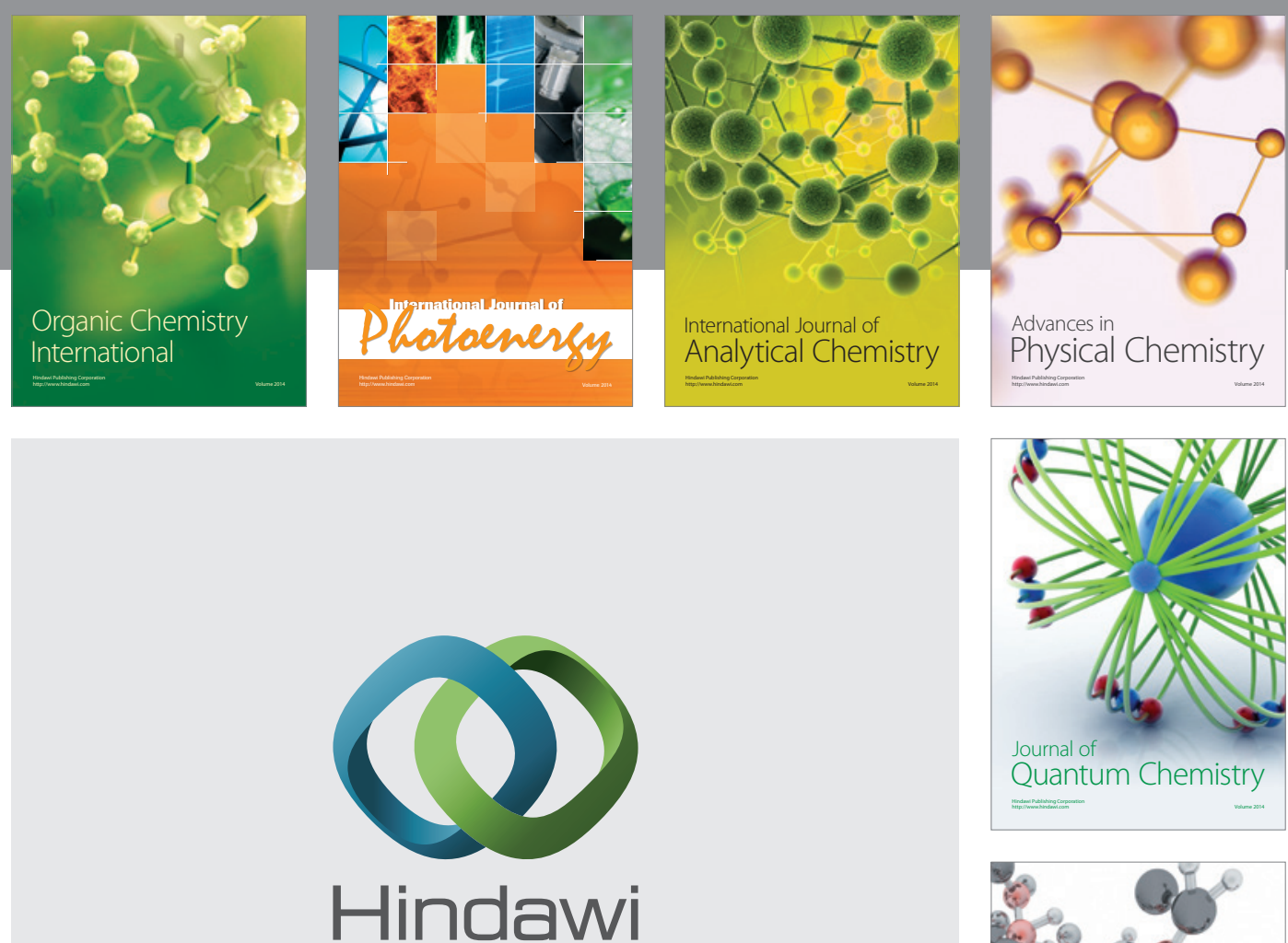

Submit your manuscripts at

http://www.hindawi.com

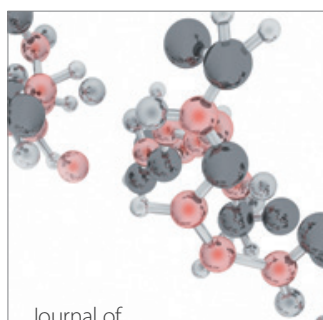

Analytical Methods

in Chemistry

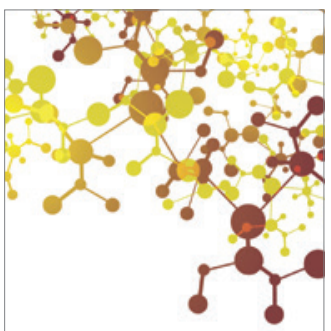

Journal of

Applied Chemistry

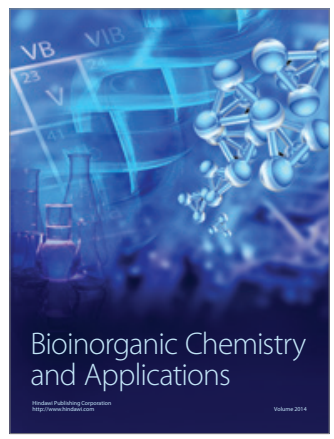

Inorganic Chemistry
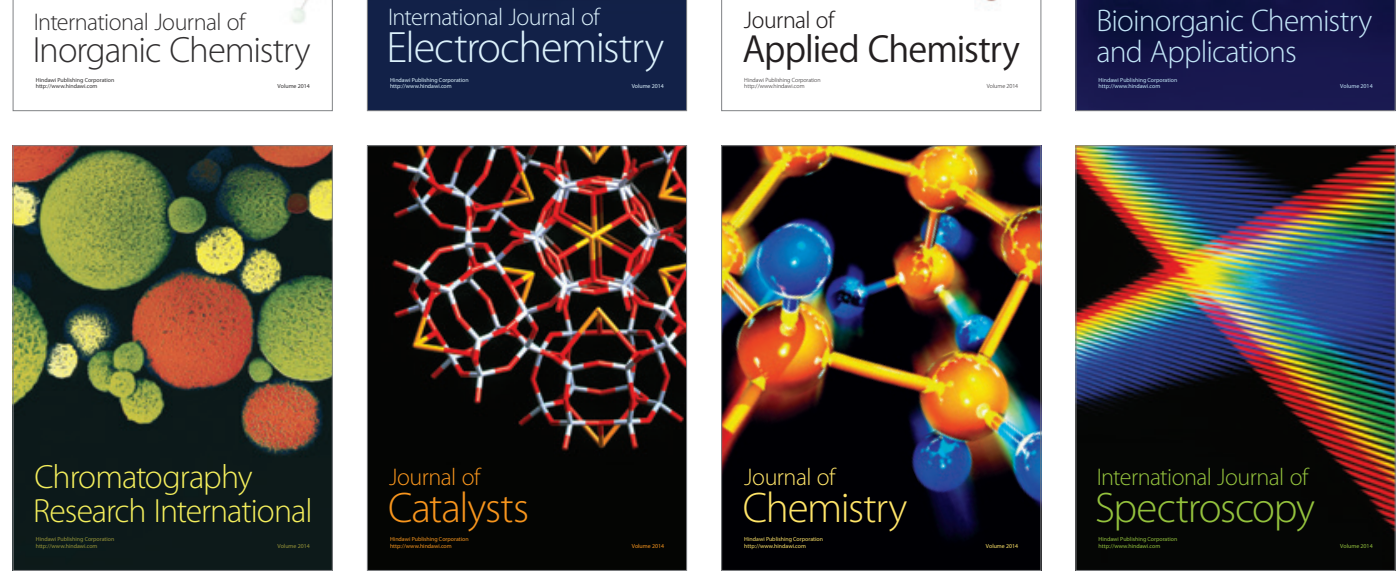